\title{
DETERMINING THE TEMPERATURE TREND OVER MARMARA REGION BY USING DATA SET FOR 1996- 2006 PERIOD
}

DOI: http://dx.doi.org/10.18509/GBP.2015.01

UDC: 551.524(560.1),,1996-2006“"

\author{
Nilcan Akataş ${ }^{1}$ \\ Serhan Yeşilköy ${ }^{1,2}$ \\ Assoc. Prof. Dr. Alper Ünal ${ }^{3}$ \\ ${ }^{1}$ Istanbul Technical University, Faculty of Aeronautics and Astronautics, Department of \\ Meteorological Engineering, Maslak, İstanbul, Turkey \\ ${ }^{2}$ Atatürk Soil, Water and Agricultural Meteorology Research Station Directorate. 39010, \\ Kırklareli, Turkey. \\ ${ }^{3}$ Istanbul Technical University, Eurasia Institute of Earth Sciences. 34469, Maslak, Istanbul, \\ Turkey.
}

\begin{abstract}
Temperature is one of the most significant variables of the climate and weather. Changing temperature patterns has been gaining big concern as a global climate change indicator. Thus, temperature data for 1996 and 2006 of 12 meteorological observation stations (Bandirma, Bursa, Canakkale, Dursunbey, Edirne, Edremit, Florya, Kirecburnu, Kirklareli, Sakarya, Tekirdag, Yalova) located in the northwest of Turkey were examined in this study to state if there is a significant trend over this region by using Mann Kendall trend test. Although, positive or negative trends of temperature exist for stations individually, statistically significant trend on regional basis is not determined.
\end{abstract}

Keywords: Temperature, Marmara Region, trend analysis, Mann Kendall

\section{INTRODUCTION}

Temperature is one of the most significant variables of the climate and weather. Climate change issue has been gaining big concern due to change of temperature on Earth. The Marmara Region which is located in the northwest of Turkey is a region that short and long term climate change can be observed. Thus, it is aimed to determine if statistically significant trend in temperature data throughout the Marmara Region exists or not by using RStudio statistical analysis program.

In the literature, there are lots of studies on trend analysis. For instance, study of Gan states that results from applying Kendall's test to temperature and precipitation data from 37 weather stations, along with 50 sets of natural stream flow data and 13 sets of evapotranspiration, data show that the Canadian Prairies have become warmer and somewhat drier in the last 4-5 decades [1]. In the study of Stafford et al. temperature and precipitation records from 1949 to 1998 were examined for 25 stations throughout the State of Alaska. The highest increases were found in winter in the Interior region $\left(2.2^{\circ} \mathrm{C}\right)$ for the 50 year period of record. Decreases in annual and seasonal mean diurnal temperature range were also found, of which only about half were statistically significant [2]. Loehle states that, Global satellite data is analyzed for temperature trends for the period January 1979 through June 2009. Beginning and ending segments show a cooling trend, while the middle segment evinces a warming trend [3]. In the study of Bani-Domi, lag-one serial correlation and Mann-Kendall rank tests are performed to understand any 
existence of possible deterministic and stochastic climatic trends in Jordan. These trends are not statistically significant, except mean minimum temperature in Amman Airport station [4].

\section{STUDY AREA AND DATA}

In this study, the daily average temperature data for years between 1996 and 2006 of 12 meteorological observation stations located in the northwest of Turkey were used (Figure 1). Mean temperature of study period were indicated on the figure.

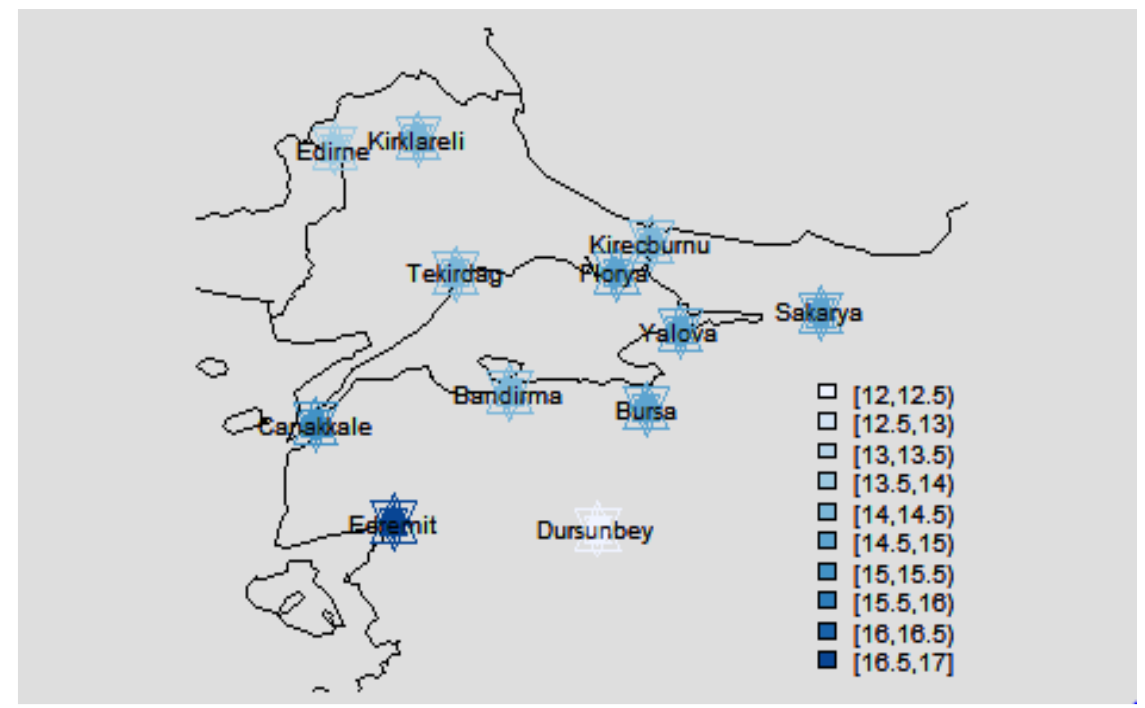

Figure 1. Locations of 12 Meteorological Observations Stations In Marmara Region with their mean temperatures between the period 1996-2006.

\section{DATA ANALYSIS}

In order to make statistical analysis to 1996 - 2006 daily temperature data, RStudio which is applied and an integrated development environment (IDE) for $\mathrm{R}$ which works with the standard version of $\mathrm{R}$ available from CRAN. RStudio includes a wide range of productivity enhancing features and runs on all major platforms [5].

First of all, box plots of twelve meteorological station data are drawn to see the smallest and largest observation, lower and quartiles. Box plots are shown in Figure 2. According to box plots, temperatures belonging to observation station have similar character and vary between $-10{ }^{\circ} \mathrm{C}$ and $30{ }^{\circ} \mathrm{C}$, approximately. Temperature data taken from Kirklareli and Edremit stations are more variable when comparing the rest of all. In addition, Edremit station has slightly higher temperature. 


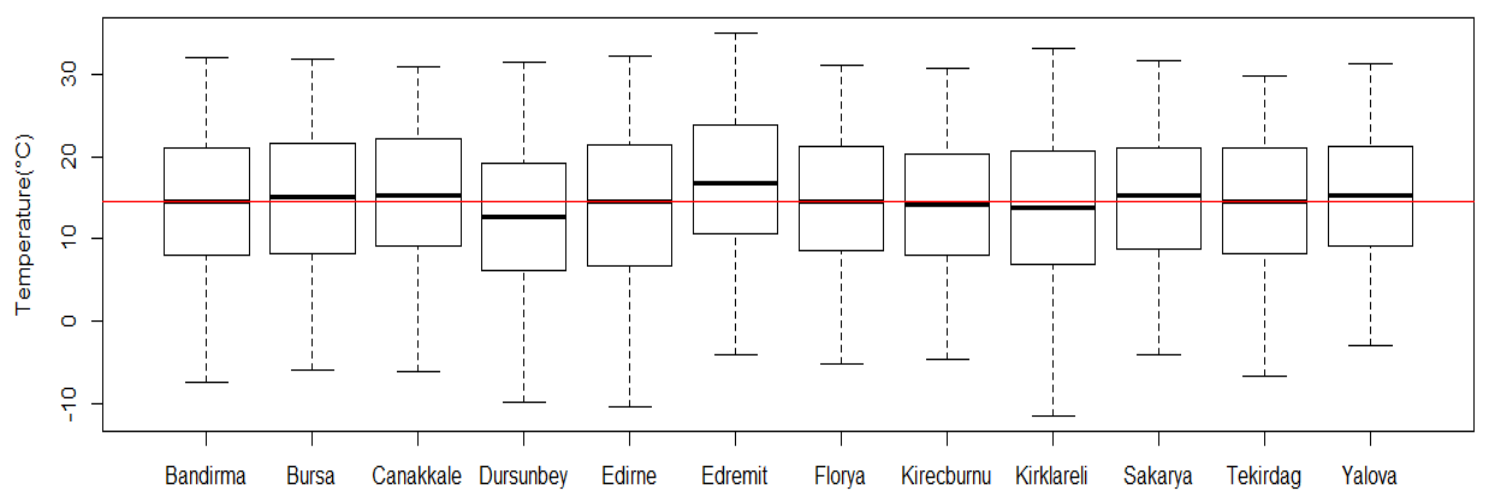

Figure 2: Box plots of 12 Meteorological Stations' Data.

Information about the box plots of all station are given in Figure 3. Interquartile range used to summarize the extent of spread of the data is close to each station.

\begin{tabular}{|c|c|c|c|c|c|c|c|}
\hline Bandirma & Bursa & canakkale & Dursunbey & Edirne & Edremit & Florya & Kirecburnu \\
\hline Min. $\quad:-7.40$ & Min. $\quad:-5.90$ & Min. $\quad:-6.2$ & Min. $:-9.90$ & Min. $\quad:-10.40$ & Min. $\quad:-4.20$ & Min. $\quad:-5.30$ & Min. $\quad:-4.60$ \\
\hline 1st Qu. : 8.00 & 1st Qu. : 8.10 & 1st Qu. : 9.2 & 1st Qu.: 6.20 & 1st Qu.: 6.70 & 1st Qu. : 10.60 & 1st Qu.: 8.60 & 1st Qu. : 8.00 \\
\hline Median :14.60 & Median :15.00 & Median :15.3 & Median :12.60 & Median : 14.50 & Median :16.70 & Median :14.60 & Median :14.20 \\
\hline Mean $: 14.38$ & Mean $: 14.74$ & Mean $: 15.3$ & Mean $: 12.42$ & Mean : 13.91 & Mean $: 16.94$ & Mean $: 14.62$ & Mean : :14.06 \\
\hline 3rd Qu. : 21.10 & 3rd Qu. : 21.60 & 3rd Qu. : 22.1 & 3rd Qu. : 19.10 & 3rd Qu. : 21.40 & 3rd Qu. : 23.80 & 3rd Qu. : 21.20 & 3rd Qu. : 20.40 \\
\hline $\begin{array}{c}\text { Max. }: 32.00 \\
\text { Kirklareli }\end{array}$ & $\begin{array}{c}\text { Max. } \quad: 31.90 \\
\text { Sakarya }\end{array}$ & 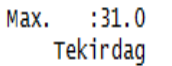 & $\begin{array}{c}\text { Max. } \begin{array}{c}\text { :31. } 50 \\
\text { Yalova }\end{array}\end{array}$ & Max. $\quad: 32.30$ & Max. $\quad: 35.00$ & Max. $\quad: 31.20$ & Max. $\quad: 30.70$ \\
\hline Min. $\quad:-11.50$ & Min. $\quad:-4.10$ & Min. $\quad:-6.70$ & Min. $\quad:-3.00$ & & & & \\
\hline 1st Qu.: 6.80 & 1st Qu.: 8.80 & 1st Qu. : 8.10 & 1st Qu. : 9.10 & & & & \\
\hline Median : 13.80 & Median :15.20 & Median :14.60 & Median :15.20 & & & & \\
\hline Mean : 13.46 & Mean $: 14.76$ & Mean :14.23 & Mean $: 14.98$ & & & & \\
\hline 3rd Qu. : 20.70 & 3rd Qu. :21.00 & 3rd Qu. :21.00 & 3rd Qu. : 21.20 & & & & \\
\hline Max. : 33.10 & Max. $: 31.60$ & Max. $\quad: 29.90$ & Max. $: 31.40$ & & & & \\
\hline
\end{tabular}

Figure 3. Summary of 12 Meteorological Stations' Data

The data in Figure 3. Indicate the variation of temperature due to changing spatial location. Mean of all individual stations are close to the median of all stations calculated as 14.48 for the period covering the years between 1996 and 2006. Because box plots look symmetric and mean of all data is about the same as the median almost all stations except Edremit and Dursunbey stations. However, the difference of median and total mean for these stations are not much. Thus it is expected that data is normally distributed. Figure 4. shows the histogram of mean temperature data including all stations' data. As it was epected, the distribution is close to a normal distribution.

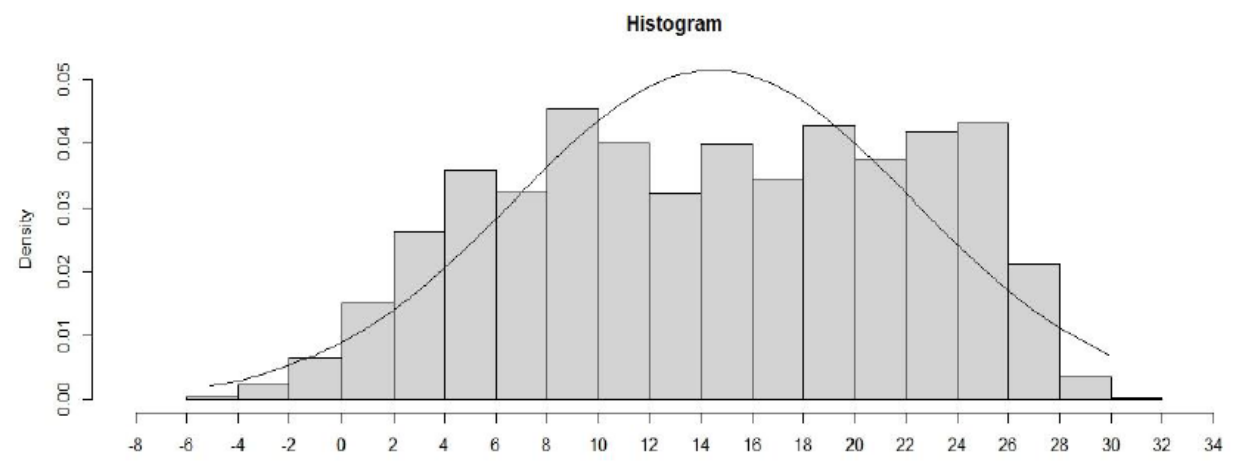

Figure 4. Frequency of Temperature Data

Then, time series of temperature data of each meteorological observation stations were examined. As shown in Figure 5, time series of all stations have similar periodicity and seasonal oscillations overlap. So that, maximum temperature values are reached in 
summer months, on the other hand minimum temperature values are reached in winter months. Generally, Kirklareli has the lowest minimum temperature values and Edremit has the maximum temperature values.

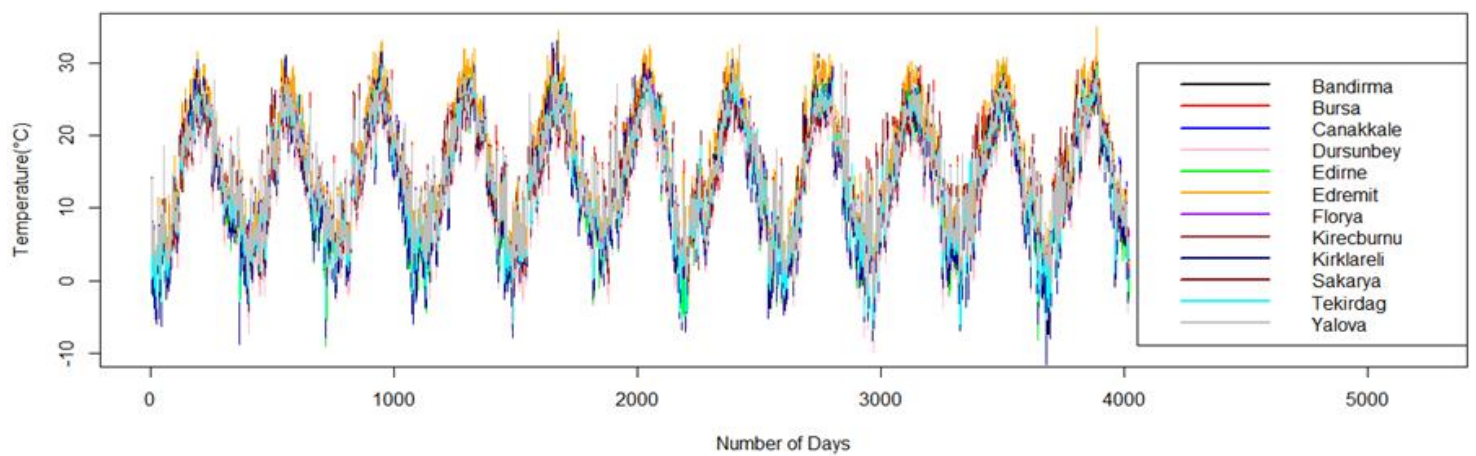

Figure 5. Time Series of 12 Meteorological Observation Stations between the years 1996-2006

In order to estimate if Kirklareli and Edremit stations are distinct from the others, Bon Ferroni test is applied as seen in Figure 6.

\begin{tabular}{|c|c|c|c|c|c|c|c|c|c|c|c|}
\hline & Bandirma & Bursa & Canakkale & Dursunbey & Edirne & Edremit & Florya & Kirecburnu & Kirklareli & sakarya & Tekirdag \\
\hline Bursa & 1.00000 & - & - & - & - & - & - & - & - & $=$ & - \\
\hline nakkale & $1.1 \mathrm{e}-05$ & 0.10156 & - & - & - & - & - & - & - & - & - \\
\hline irsunbey & $<2 \mathrm{e}-16$ & $<2 \mathrm{e}-16$ & $<2 \mathrm{e}-16$ & - & - & - & - & - & - & - & - \\
\hline irne & 0.46876 & 0.00013 & 1. $5 e-13$ & $1.4 e-15$ & - & - & - & - & - & - & - \\
\hline Iremit & $<2 \mathrm{e}-16$ & $<2 \mathrm{e}-16$ & $<2 \mathrm{e}-16$ & $<2 \mathrm{e}-16$ & $<2 \mathrm{e}-16$ & - & - & - & - & - & - \\
\hline ory & 1.00000 & 1.00000 & 0.00837 & & 0.00282 & $\mid<2 e-16$ & - & - & - & - & - \\
\hline recburnu & 1.00000 & 0.00638 & $1.1 \mathrm{e}-10$ & $<2 \mathrm{e}-16$ & 1.00000 & $\mid<2 \mathrm{e}-16$ & 0.08072 & - & - & - & - \\
\hline Kirklareli & $1.1 \mathrm{e}-05$ & 1. $9 \mathrm{e}-11$ & $<2 \mathrm{e}-16$ & 1. $8 \mathrm{e}-07$ & 0.73032 & & 2.2e-09 & 0.04 & - & - & - \\
\hline Eak & 1.00000 & 1.00000 & 0.15277 & $<2 \mathrm{e}-16$ & $7.1 \mathrm{e}-05$ & $<2 \mathrm{e}-16$ & 1.00000 & 0.00385 & $7.9 e-12$ & - & - \\
\hline Tekirdag & 1.00000 & 0.22413 & $7.2 \mathrm{e}-08$ & $<2 \mathrm{e}-16$ & 1.00000 & $<2$ & 1.00000 & 1.00000 & & 0.15097 & - \\
\hline Yalova & 0.04351 & 1.00000 & 1.00000 & $<2 \mathrm{e}-16$ & $7.1 \mathrm{e}-08$ & $<2 \mathrm{e}-16$ & 1.00000 & 1. $1 \mathrm{e}-05$ & $3.9 e-16$ & 1.00000 & 0.00129 \\
\hline
\end{tabular}

$P$ value adjustment method: bonferroni

Figure 6. Bon Ferroni Test

According to test results, because P values between Kirklareli and the other stations are always smaller than 0.05 , comparison is statistically significant. Test results has showed that temperature data of Edremit station are apparently distinct from the others, although correlations are high (Figure 7). Correlations are very high and determination coefficients are generally over $96 \%$ due to closeness of the stations' locations.

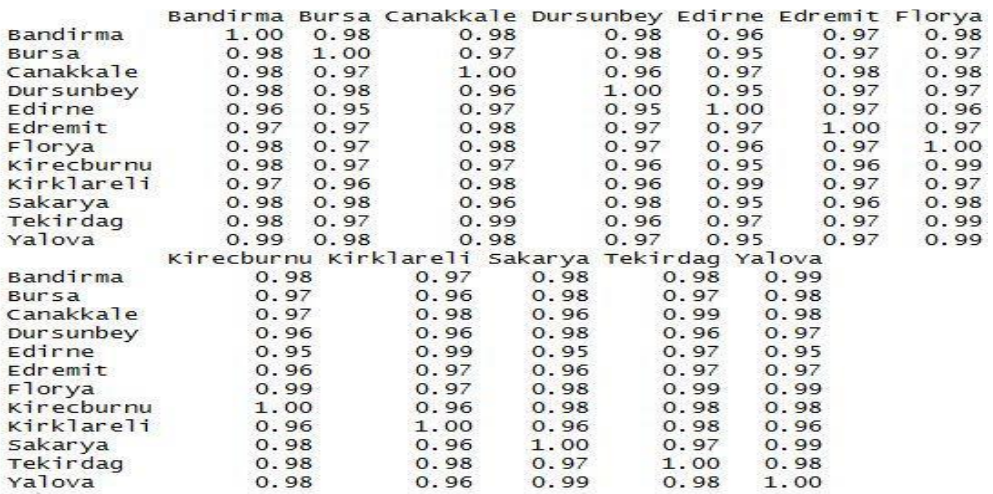

Figure 7. Correlation Coefficient between the Stations 


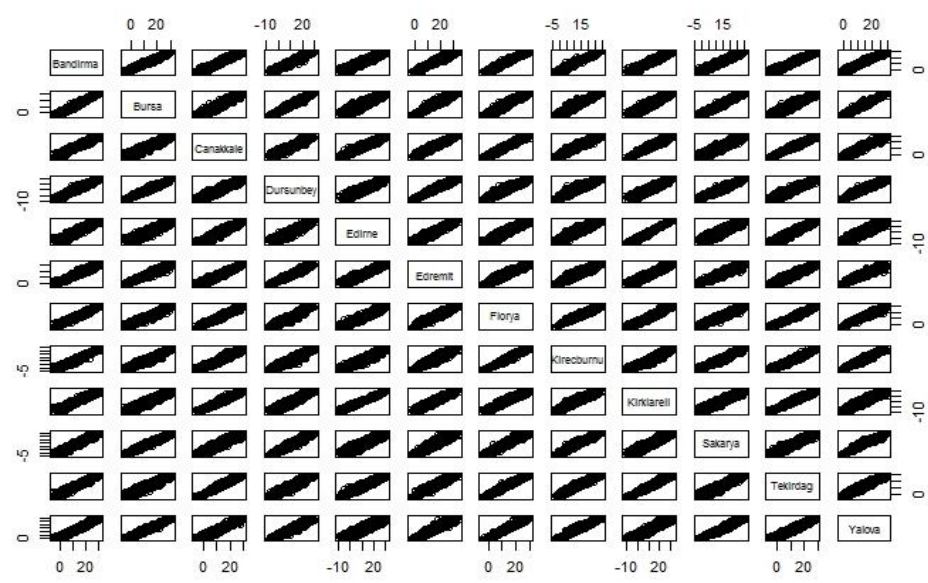

Figure 8. Scatter Diagram of Stations' Temperature Data

Scatter diagram matrix of the previously given years' temperature data on the twelve stations shown in Figure 8. It shows that there are strong relationships between temperature data of stations for 1996 - 2006 years.

Because variables are correlated with one another, it would be possible to reduce the observed temperature values into a smaller number of principle components. Thus, principle component analysis method is applied.

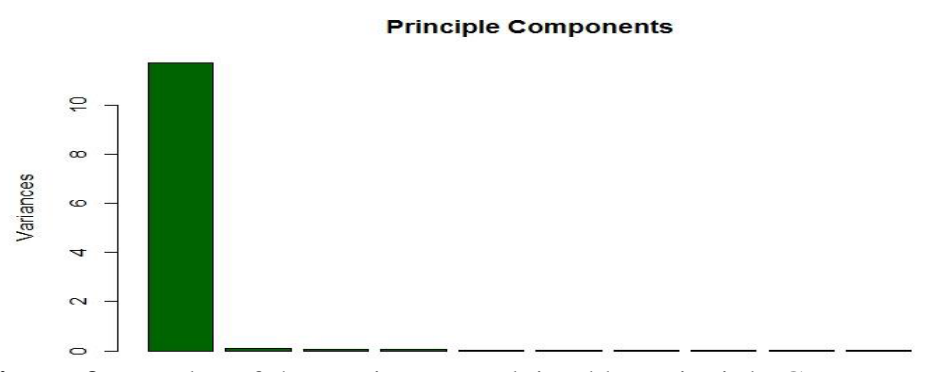

Figure 9. Barplot of the Variance Explained by Principle Components

A barplot of each component's variance shows how the first component dominates. A plot of the data in the space of the first two principal components, with the points labelled by the name of the corresponding competitor can be produced as shown with Figure 10.

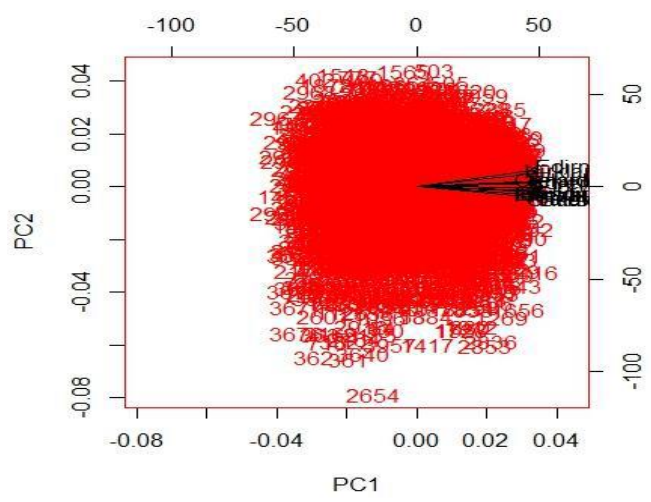

Figure 10. Biplot of the first two principal components

The first principal component is in good agreement with the score assigned to the temperature; a scatterplot of the temperature data and the first principal component is 
given in Figure 11. The linear relation between temperature data and first principle component was given in Figure 12.

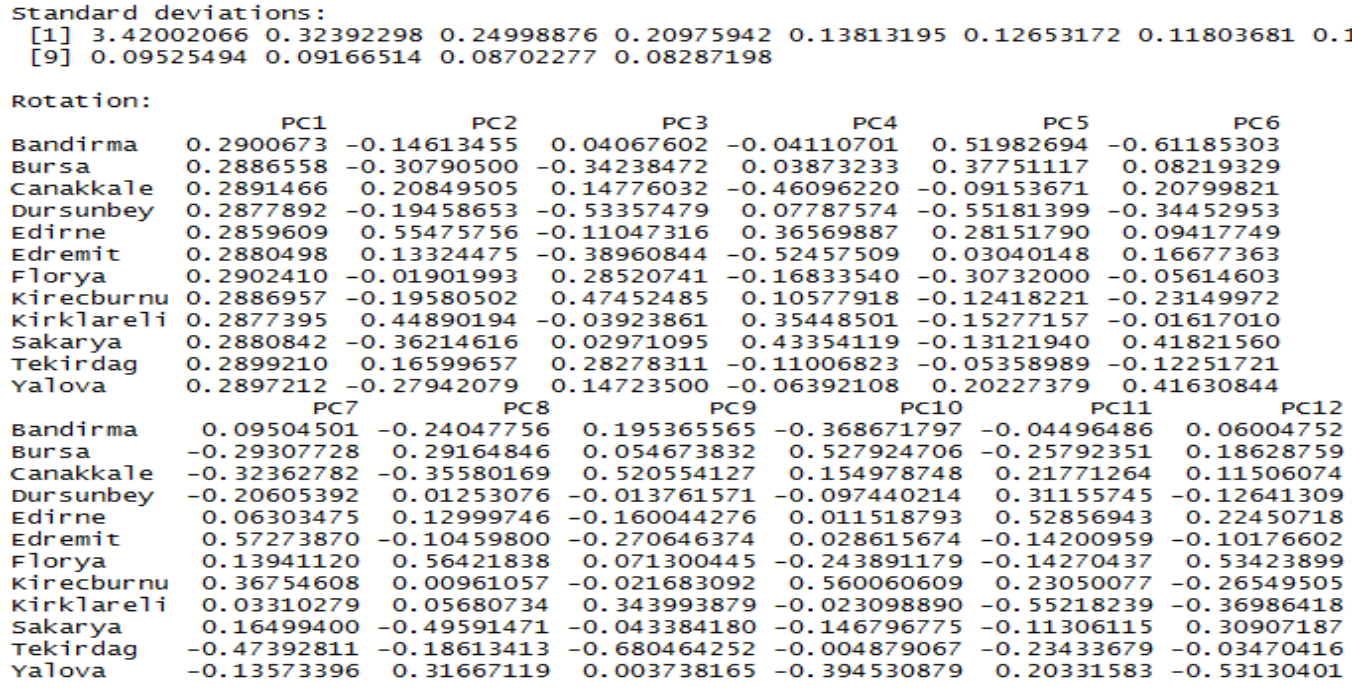

Figure 11. Principle Components for each Stations

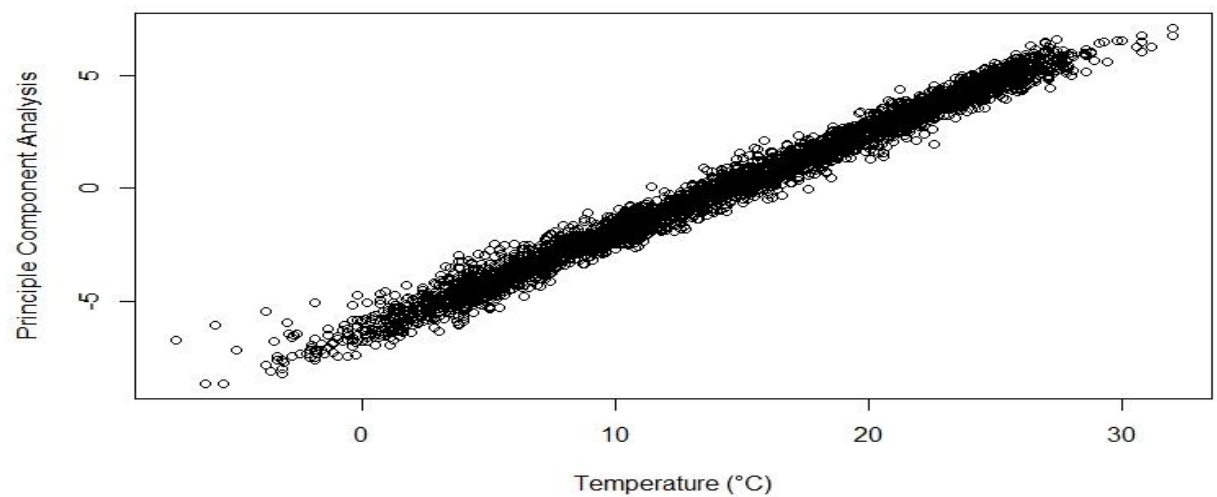

Figure 12. Scatterplot of the temperature data between 1996-2006 years and the first principle component

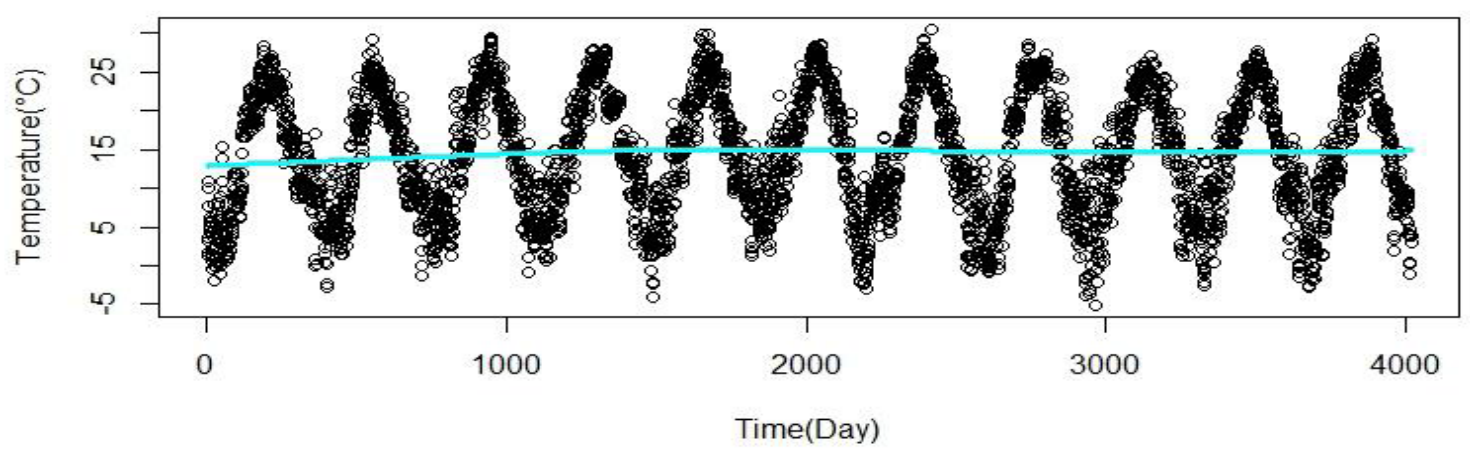

Figure 13. Time Series of Temperature Data

Time series of temperature data is given in Figure 13 with the mean indicated by blue line. In the graph, seasonal oscillations can be seen, so it is aimed to deseasonalize the data. 


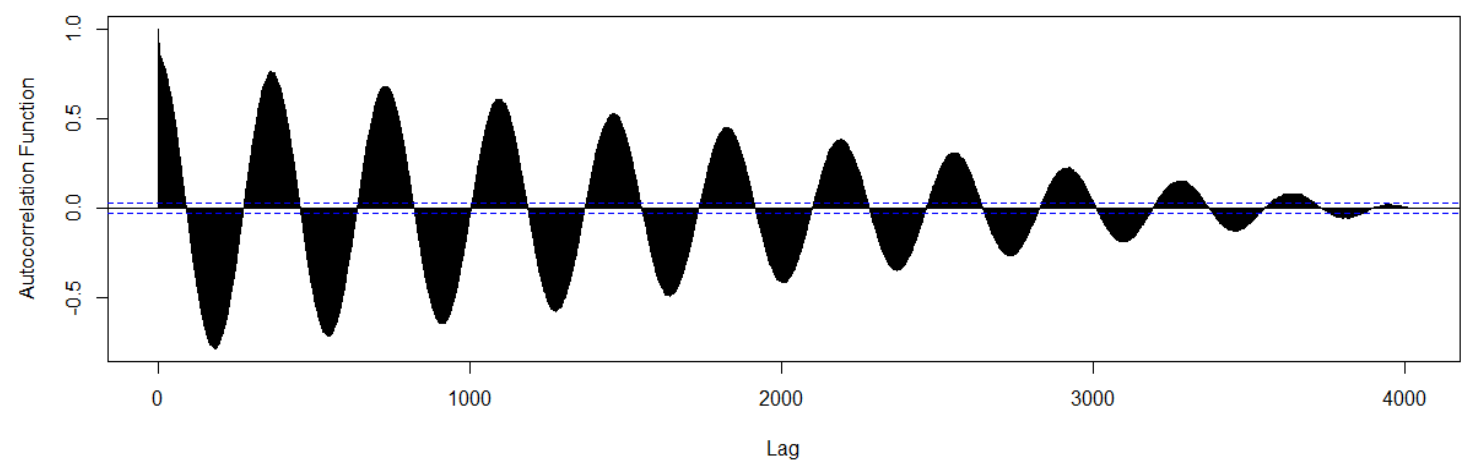

Figure 14. Autocorrelation Function

Autocorrelation function is given in Figure 14. It implies that autocorrelation between temperature data is always above zero. It is expected to be incorrect calculation of error terms. Thus, it is performed Durbin-Watson test to mean temperature data of the stations to determine the correlation coefficient, $d$. It was assumed that if $\mathrm{d}$ is equal zero, $\mathrm{H}_{0}$ hypothesis is accepted so that there is no correlations between errors. However, in our study Durbin Watson Test coefficient was determined as 0.01930465 which is greater than zero. In this situation, $\mathrm{H}_{0}$ hypothesis is rejected and existing of correlation between errors is accepted according to $\mathrm{H}_{1}$ hypothesis. Because of this reason alternative two sided test is performed and deseasonalize the time series of the data then error term is decreased as seen in Figure 15 and Figure 16.

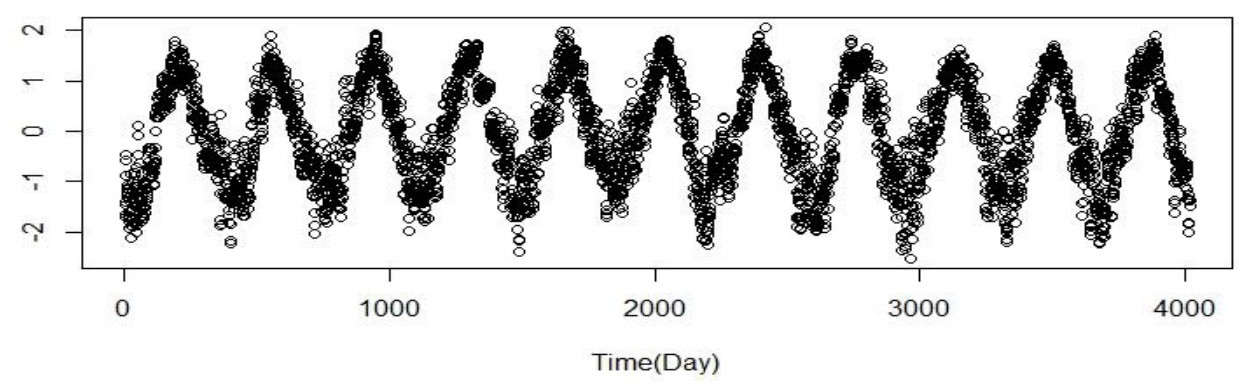

Figure 15. Deseasonalized Time Series

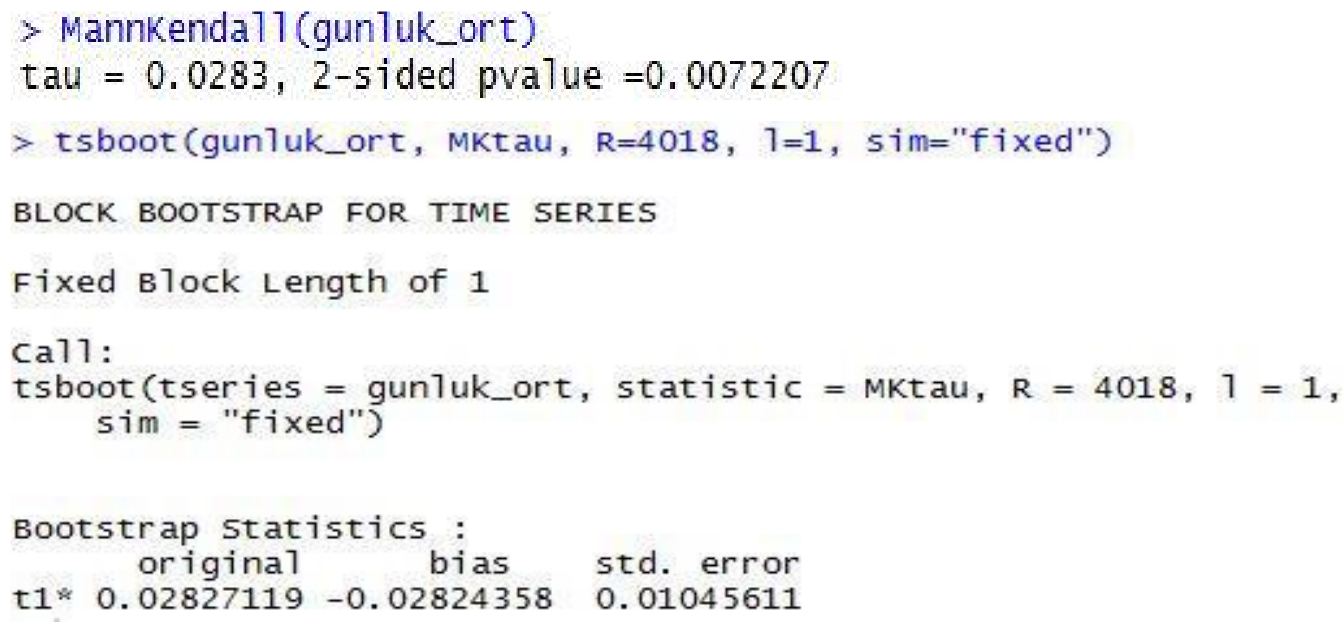

Figure 16. Block Bootstrap for Time Series

\section{CONCLUSION}


As a result of data analysis, using daily mean temperature of twelve meteorogical observation stations of Marmara Region in eleven-year period, existing of a trend was examined. Boxplot of all stations showed that nearly all stations have the similar behavior. Because median of the stations and the general mean are almost the same, it can be assumed that temperature data of the stations are normally distributed.

According to correlation analysis, stations' data are found distinctly correlated. Considering all data, they are also autocorrelated. In order to fix this problem in term of statistics, it is aimed to diminish the standard deviation of errors. In addition, data was made deseasonalized. Standard deviation of errors is decreased from 0.02827 to 0.1045. In this instance, calculations were done again and applied Mann Kendall Trend Test. It is not detected statistically significant positive or negative trend for eleven-year period of 1996 - 2006 temperature data over the Marmara Region.

\section{REFERENCES}

[1] Gan T. Y. 1998. Hydroclimatic trends and possible climatic warming in the Canadian Prairies. Water Resources Research, Volume 34, Issue 11, pages 3009-3015.

[2] Stafford, J. M., Wendler, G. and Curtis, J. 2000. Temperature and precipitation of Alaska: 50 year trend analysis, Theor. Appl. Climatol. 67, 33-44.

[3] Loehle, C. 2009. Trend Analysis of Satellite Global Temperature Data, Energy \& Environment Vol. 20, No. 7, 2009.

[4] Bani-Domi, M. 2005. Trend Analysis of Temperatures and Precipitation in Jordan. Umm Al-Qura University Journal of Educational, Social Sciences \& Humanities Vol. 17-No.1.

[5] Url-1 < http://www.rstudio.com/ide/docs/faq>, Retrieved time: 08.02.2013. 